4. Линденау Я.И. Описание народов Сибири (первая половина XVIIIв.). Историко-этнографические материалы о народах Сибири и Северо-Востока. - Магадан: Магаданское кн. изд-во, 1983.С. 66.

5. Василевич Г.М. Эвенки: Историко-этнографические очерки (XVIII - нач. XX вв.) - Л.: Наука, 1969. C. 173.

6. Белянская М.Х. Сокровенные основы семейного благополучия в традиционной культуре эвенов // История и педагогика естествознания, 2016. С. 63.

7. Пекарский Э.К., Цветков В.П. Очерки быта приаянских тунгусов // Сборник МАЭ. СПб.: Типография Императорской Академии наук, 1913. Вып. II. Т. 1. С. 231.

8. Ермолова Н.В. Заметки о жизни оленеводов эвенкийского поселка Суринды (из полевых наблюдений 2009 года) // Материалы полевых исследований МАЭ РАН. Вып.10. СПб.: МАЭ РАН, 2010. C. 39.

9. Алехин К.А. Этнокультурная характеристика локального сообщества. Проблемы коммуникативной культуры : На материале эвенков Суринды : автореферат дис. ... кандидата исторических наук : 07.00.07 / Ин-т археологии и этнографии Сибирского отделения РАН. Новосибирск, 2001. С. 100.

10. Васильев В.Н. Предварительный отчет о работах среди Алдано-Майских и Аяно-Охотских тунгусов в 1926-1928 годах. - Л.: Изд-во Акад. наук СССР, 1930. - Вып. 36. С. 74.

11. Иванищенко В.Ф. Живой календарь эвенков Амурской области // Эвенкийский этнос в начале третьего тысячелетия. Сборник научных трудов. Вып. 2. Благовещенск: Изд-во БГПУ, 2008. С. 243.

\title{
Алышев И.В. \\ К вопросу о значимости развития въездного и внутреннего туризма для Великобритании
}

Хакасский государственный университет им. Н.Ф. Катанова (Россия, Абакан)

doi: 10.18411/lj-04-2021-268

Научный руководитель

Баранцева Н.А.

\section{Аннотация}

Работа посвящена рассмотрению вклада иностранных и отечественных туристов в туриндустрию Великобритании. В статье, помимо этого рассмотрены основные аспекты въездного и внутреннего туризма.

Ключевые слова: туристическая индустрия, Великобритания, въездной туризм, внутренний туризм.

\section{Abstract}

The work is devoted to the consideration of the contribution of foreign and domestic tourists to the UK travel industry. In addition, the article discusses the main aspects of inbound and domestic tourism.

Key words: tourism industry, Great Britain, inbound tourism, domestic tourism.

Сфера туризма зародилась в Англии. Как отмечает Логинова Н. Ю.: «Великобритания - родина современного туризма как формы проведения культурного досуга» [6]. Первое туристическое агентство в истории было основано в начале 40-х гг. XIX в. в Англии Томасом Куком [7]. А уже в 1856 г. была организована и осуществлена первая групповая туристическая поездка в страны Западной Европы. Эту дату принято считать началом международного туризма [8].

В настоящее время Великобритания, несмотря на потерю сразу нескольких позиций в рейтинге самых популярных стран туристических направлений, все равно остается в десятке стран, которые посещают туристы. Общее количество туристов в 2018 г., посетивших «Туманный Альбион», составило боле 35 млн чел. [1].

Туристическая отрасль очень важна для Англии, т.к. значительная часть населения работает в данной сфере. Так, по данным отчета Туристического Альянса 
(The Tourism Alliance) за 2019 г., в стране зарегистрировано более 241000 компаний в туриндустрии. Всего сфере туризма занято 3,3 млн людей, из которых 1,4 млн работают полный рабочий день, 1,3 млн - неполный и 0,6 млн людей ненормированный рабочий день. На постоянной основе работают $90 \%$ сотрудников. Для сравнения в производственной и строительной сферах задействовано 2,9 млн и 2,4 млн чел. соответственно. За последние 10 лет туриндустрия создала более 400000 рабочих мест. В 2019 г. отрасль пополнила бюджет страны на 3,6 млрд фунтов стерлингов [2].

Очевидна значимость иностранных туристов для страны. Важно выяснить из каких стран они приезжают, и какие места предпочитают посещать.

Самыми важным поставщиком туристов для Великобритании является Европа 70\% тех, кто находится в Англии с целью отдыха. Европейское представительство выше среди тех, кто остается за пределами Лондона, особенно в прибрежных городах $84 \%$. Посетителей из Северной Америки около 20\%, от $10 \%$ - остальной мир [3].

За 2018 г. количество посещений страны упало на 3\% до 37, 9 млн человек (в 2017 г. установлен рекорд посещаемости 39,2 млн) после стабильного роста с 2010 г. Значительно снизились и общие расходы туристов, снижение произошло на 7\% до 22,9 млрд фунтов стерлингов [13].

Основные страны, которые поставляют туристов в Великобританию

\begin{tabular}{|c|c|c|c|c|c|c|}
\hline \multicolumn{4}{|c|}{ Десятка крупнейших рынков по объему посещений } & \multicolumn{3}{|c|}{$\begin{array}{c}\text { Десятка крупнейших рынков по объему } \\
\text { расходов }\end{array}$} \\
\hline № & Страна & Посещений & $\begin{array}{c}\text { \% от всех } \\
\text { посещений }\end{array}$ & Страна & $\begin{array}{c}\text { Траты в млн } \\
\text { фунтов } \\
\text { стерлингов }\end{array}$ & $\begin{array}{r}\% \text { от всех } \\
\text { расходов }\end{array}$ \\
\hline 1 & $\begin{array}{c}\text { Соединенные } \\
\text { Штаты } \\
\text { Америки }\end{array}$ & 3877 & $10 \%$ & $\begin{array}{c}\text { Соединенные } \\
\text { Штаты Америки }\end{array}$ & 3378 & $15 \%$ \\
\hline 2 & Франция & 3693 & $10 \%$ & Германия & 1520 & $7 \%$ \\
\hline 3 & Германия & 3262 & $9 \%$ & Франция & 1386 & $6 \%$ \\
\hline 4 & $\begin{array}{l}\text { Ирландская } \\
\text { Республика }\end{array}$ & 2782 & $7 \%$ & Испания & 1110 & $5 \%$ \\
\hline 5 & Испания & 2530 & $7 \%$ & Австралия & 1044 & $5 \%$ \\
\hline 6 & Нидерланды & 1954 & $5 \%$ & $\begin{array}{l}\text { Ирландская } \\
\text { республика }\end{array}$ & 895 & $4 \%$ \\
\hline 7 & Польша & 1817 & $5 \%$ & Италия & 784 & $3 \%$ \\
\hline 8 & Италия & 1808 & $5 \%$ & Нидерланды & 716 & $3 \%$ \\
\hline 9 & Бельгия & 1116 & $3 \%$ & Канада & 676 & $3 \%$ \\
\hline 10 & Австралия & 1003 & $3 \%$ & Китай & 657 & $3 \%$ \\
\hline
\end{tabular}

Из приведенной выше таблицы видны явные лидеры по посещаемости Великобритании как в количестве посещений страны, так и в сумме потраченных средств. Соединенные Штаты занимают первое место среди стран, попавших в рейтинг. И если по объему посещений показатели США примерно равны показателям Франции и Германии, незначительно превышая их, то в потраченных деньгах американцы опережают страны Европы более, чем в 2 раза.

Эти показатели объясняются несколькими факторами. Во-первых, США находятся на значительном удалении от Великобритании по сравнению с такими странами как Франция и Германия, это обусловливает небольшие показатели в количественном эквиваленте. Необходимо учитывать, что население Соединенных Штатов Америки 328 млн ЧЕЛОВЕК, Франции 66 млн, а Германии 83 млн. Можно предположить, что путешествие в Англию могут позволить себе состоятельные американцы, что частично объясняет их высокие траты. Во-вторых, говоря о расходах, следует учитывать менталитет людей, цели и места их пребывания. 
Говоря о Российской Федерации, следует отметь, что по данным «Российского Союза Туристической Индустрии», россияне стали больше тратить во время поездок в Великобританию. По мнению Хорешок Т. (руководитель британского управления по туризму «Visit Britain» в России), россиян привлекает разнообразная культура страны, ее богатое и яркое историческое наследие [4]. Даринский А.В. указывает: «Для многих образ Британии складывается на уроках английского языка, когда страна изучается в культурном и историческом аспекте. Именно поэтому большинство из наших соотечественников в первый свой визит в Британию стараются посетить «знакомые» с детства места: Тауэр и Тауэрский мост, Биг-Бен, собор Святого Павла, Букингемский дворец и прочее» [5].

В провиденной ниже диаграмме видно, что большинство туристов посещают Великобританию для того, чтобы провести отпуск и отдохнуть, а также с целью встречи с родственниками или друзьями. Однако велика доля и тех, кто посещает страну с деловым визитом, т.к. столица Англии Лондон не только культурный, но и важнейший финансовый центр в мире.

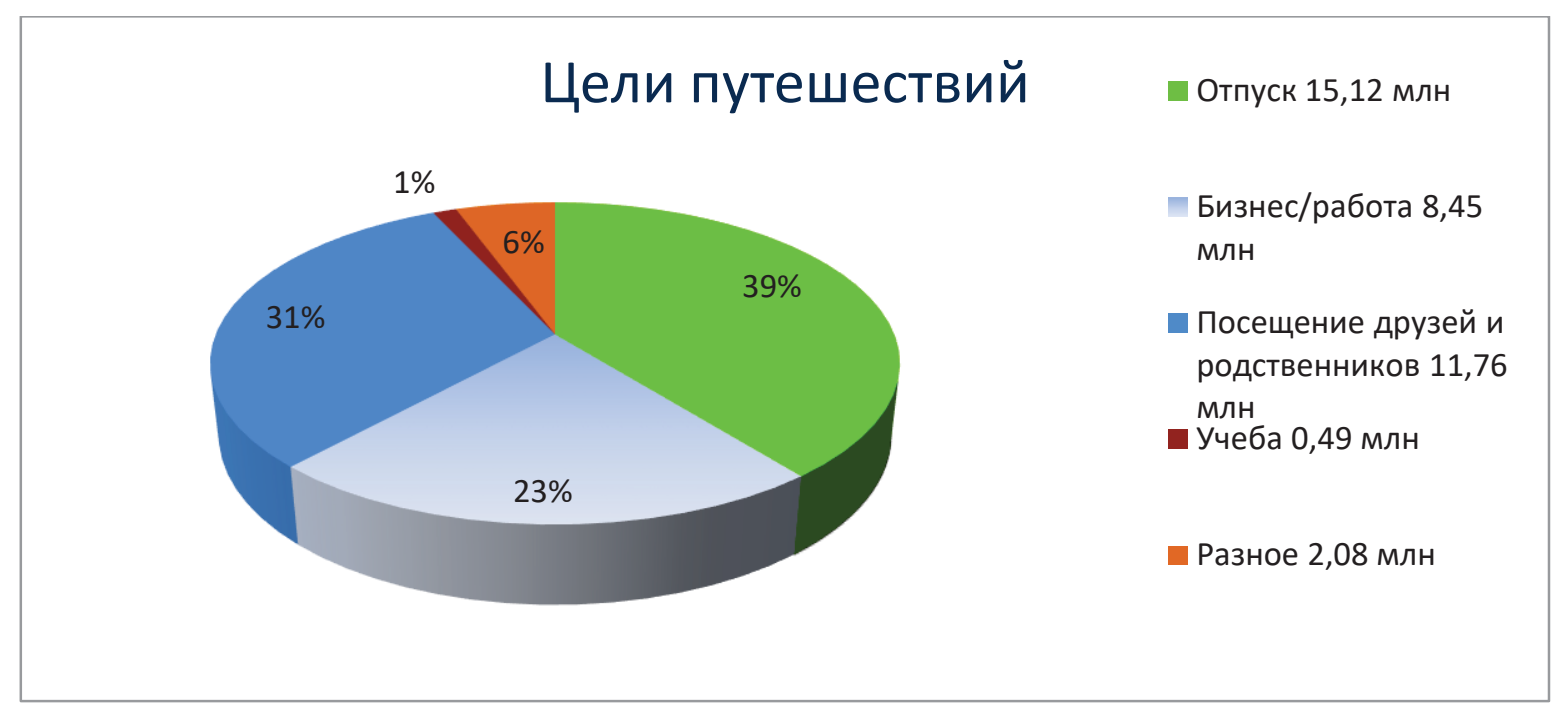

Табл. 2. Источник: Официальный сайт VisitBritain: https://www.visitbritain.org/inbound-tourism-trends

Данные диаграммы объясняют сезонность посещений страны. Больше всего пребываний туристов приходится на июль-сентябрь (10,80 млн - 28,50\%), затем апрель-июнь (10, 06 млн - 26,53\%) и октябрь-декабрь (9,16 млн - 24,17\%). Меньше всего турпоток в январе-марте (7,88 млн - 20,80\%) [13].

Стоит отметить, что именно в праздничные дни увеличивается турпоток. Многие прибывшие туристы предпочитают остаться в Лондоне. В абсолютных цифрах (в тыс. чел.) для разных стран и регионов это выглядит следующим образом: Франция 1070, США - 940, Скандинавия - 912, Германия -732, Италия - 670, Испания - 539 [3].

Подводя промежуточный итог, можно сказать, что иностранные туристы играют существенную роль для Великобритании с точки зрения финансовой прибыли, которая росла на протяжении нескольких лет подряд до 2018 г.

Значительный вклад в развитие въездного туризма Англии составляют жители таких стран как США, Франция, Германия, Норвегия, Испания и Италия. Именно эти страны составляют значительную часть туристов, посещающих Англию.

В свою очередь, у посещающих Великобританию иностранцев самые разные цели визита, начиная с проведения отпуска, заканчивая образованием и деловыми мотивами. Несомненно, сезон влияет на количество прибывших туристов, так именно в праздники и летние месяцы увеличивается турпоток в страну.

Несмотря на всю важность въездного туризма как для отрасли, так и для государства в целом, большую часть дохода и основными потребителями туристических услуг в стране остаются ее жители. Так, генеральный директор Visit 
Britain и Visit England Салли Балкомб отмечала, что «из 127 млрд фунтов стерлингов, которые ежегодно пополняют экономику Великобритании индустрия гостеприимства, 102 млрд приносит внутренний туризм» [9].

Существует ряд основных естественных причин, по которым качественно развит внутренний туризм. Например, природные ландшафты и компактное расположение городов. Логинова Н.Ю. констатирует: «В Великобритании сложились благоприятные условия для развития туризма: в стране нет районов, отстоящих от моря более чем на 120 км, то есть от одного-полутора часов езды, множество городов расположено непосредственно на побережье. В Великобритании разнообразны ландшафты, и в каждой из частей страны есть горные или холмистые районы. Огромное количество рек и озер» [6].

Высокая урбанизация населения (приблизительно около 87\% проживает в городах), а также развитая инфраструктура положительным образом влияют на развитие внутреннего туризма, т.к. предоставляются широкие возможности для путешествий как на личном, так и общественном транспорте. «Великобритания занимает одно из первых мест в мире по густоте сети автомобильных дорог - 1580 км на 1000 кв. км территории (для сравнения, в европейской части России - 400 км на 1000 кв. км) и уступает лишь Германии по густоте сети железных дорог - 70 км на 1000 кв. км территории. Парк легковых автомобилей в стране превышает 30 млн (400 на 1000 жителей и около 1,3 в среднем на семью)» [6]. Больше половины британцев совершают путешествия по стране на личных автомобилях, четверть британских туристов - на междугородних автобусах или поездах.

Одним из важных факторов развития индустрии является своевременные меры, которые предпринимает руководство страны. Например, в 2016 г. из-за увеличения числа британцев, которые проводят отдых на Родине, правительство предложило план развития, включающий пакеты туров по железной дороге, а также изменения правового характера, которые позволили владельцам пансионов угощать гостей алкоголем, не приобретая лицензию на торговлю и подвозить людей до вокзалов, не открываю службу такси [10].

Одну из важнейших ролей в туристическом бизнесе играет имидж. По мнению бывшего премьер-министра Терезы Мэй, «огромное влияние оказали Олимпийские игры. Наверное, мы были первой страной, которая осознала и использовала колоссальное наследие, которое Олимпиада дает стране - организатор» [9].

В Великобритании огромное количество знаменитых на весь мир футбольных команд и стадионов, которые привлекают фанатов со всего мира. По данным Союза европейских футбольных ассоциаций Англия входит в топ - 5 лучших футбольных лиг в мире [10]. Ежегодно в Великобританию приезжает около 3 млн туристов, чтобы посмотреть и поучаствовать в различных соревнованиях. Спортивный туризм каждый год приносит в казну приблизительно 3 млрд евро [7]. По полярности спортивного туризма футбол занимает первое место, затем расположился конный спорт, третье место занимают соревнования по гольфу.

Большинство населения Великобритании предпочитает отдыхать на Родине. Чаще всего к таким местам относится морское побережье Юго-Восточной Англии, четверть туристов отдыхает в горах Уэльса и Шотландии [12]. Популярность данных регионов среди англичан объясняется наличием турбаз для различного вида отдыха, финансовой доступностью, развитой инфраструктурой и красивыми пейзажами национальных парков и заповедников.

Отдых в национальных парках популярен не только среди иностранцев, но и среди отечественных туристов. Ежегодно их посещает около 15 млн человек. Крупнейшие национальные парки находятся в Шотландии (Нортумберленд, Нордворкмурс, Ворюдир Далес), Уэльсе (Эксмур, Дартмур) и Северной Англии (Дервент) [12]. 
Таким образом, внутренний туризм так же, как и внешний, играет важную роль в развитии туристической отрасли страны в целом. Стоит отметить, что именно граждане Великобритании являются основными потребителями туриндустрии, а, следовательно, основными источниками прибыли.

Подводя общий итог, можно сделать следующий вывод: туристическая сфера вносит значительный вклад в пополнение казны. Миллионы граждан задействованы в туриндустрии, а это означает зависимость с финансовой точки зрения от успехов или неудач как туристического сезона, которым является июль-сентябрь, так и календарного года в целом. Мы выяснили, что цели иностранных туристов самые разные, a распределение количества посещений в году примерно равное, следовательно, для отрасли важен каждый месяц, потому что судить об успешности или неудаче сезона нельзя лишь по одному периоду. Важен каждый месяц.

Наибольшими потребителями туристических услуг являются сами англичане, иностранцы занимают меньшую долю данного рынка. Тем не менее, по официальным данным можно сделать вывод о стабильном развитии как въездного, так и внутреннего туризма. В первую очередь, этому способствуют: историко-культурные факторы появление туристической отрасли в Великобритании, наличие различных памятником архитектуры; природно-географические - выгодное расположение и разнообразие национальных парков.

Таким образом, сложно переоценить значимость туриндустрии для Великобритании как с финансовой точки зрения, так и сточки зрения историкокультурного аспекта.

$$
* * *
$$

1. Ассоциация туроператоров. «20 самых посещаемых стран мира». [Электронный ресурс] / Режим доступа: URL: https://www.atorus.ru/news/press-centre/new/47175.html (дата обращения: 5.04.2020).

2. Туристический альянс (The Tourism Alliance). [Электронный ресурс] / Режим доступа: https://www.tourismalliance.com (дата обращения: 5.04.2020).

3. Британское национальное агентство по развитию туризма «Visit Britain». Отчет о предпочитаемых местах: профиль иностранных туристов, которые останавливаются в разных городах и населенных пунктах Англии [Электронный ресурс] / Режим доступа: URL: https://www.visitbritain.org/sites/default/files/vb-corporate/Documents-Library/documents/Englanddocuments/discover_england_destination_towns_v4 (дата обращения: 5.04.2020).

4. Российский Союз Туристической Индустрии [Электронный ресурс] / Режим доступа: URL: http://www.rstnw.ru/statistika-po-velikobritanii (дата обращения: 5.04.2020).

5. Даринский А.B. Туризм в Великобритании [Электронный ресурс] / Режим доступа: URL: https://geo.1sept.ru/article.php?ID=200104101 (дата обращения: 5.04.2020).

6. Логинова Н.Ю. Туристский бизнес в Великобритании: история и основные направления развития отрасли. [Электронный ресурс] / Режим доступа: URL: https://cyberleninka.ru/article/n/turistskiybiznes-velikobritanii-istoriya-i-i-osnovnye-napravleniya-razvitiya-otrasli (дата обращения: 5.04.2020).

7. Квартальнов В.А. Туризм. Учебник для образовательных учреждений туристского профиля. М.: Финансы и статистика, 2006. 335 с.

8. «Ведомости». Интервью с Салли Балкомб. [Электронный ресурс] / Режим доступа: URL: https://www.vedomosti.ru/business/characters/2019/09/10/810957-direktor-agentstva-razvitiyu-turizma (дата обращения: 5.04.2020).

9. Англия сегодня [Электронный pecypc] / Режим доступа: URL: https://www.angliya.today/puteshestvija/vnutrennij-turizm-v-velikobritanii-nabiraet-oboroty-soslableniem-funta (дата обращения: 04.05.2020).

10. УЕФА [Электронный ресурс] / Режим доступа: URL: https://ru.uefa.com/memberassociations/uefarankings/country/\#/yr/2020 (дата обращения: 05.04.2020).

11. Погодина В.Л., Филиппова И.Г. География туризма / под ред. Е.И. Богданова. М.: ИНФРА. М, 2018. $256 \mathrm{c}$.

12. Британское национальное агентство по развитию туризма «Visit Britain» [Электронный pecypc] / Режим доступа: URL: https://www.visitbritain.org/2018-snapshot (дата обращения: 05.04.2020).

13. Британское национальное агентство по развитию туризма «Visit Britain» [Электронный ресурс] / Режим доступа: URL: https://www.visitbritain.org/inbound-tourism-trends (дата обращения: 05.04.2020). 